\title{
Enhancement of Type B and A Photoreceptor Inhibitory Synaptic Connections in Conditioned Hermissenda
}

\author{
Robert J. Frysztak and Terry Crow \\ Department of Neurobiology and Anatomy, University of Texas Medical School, Houston, Texas 77225
}

Intrinsic changes have been identified in isolated and intact type $A$ and type B photoreceptors following classical conditioning of the nudibranch mollusk Hermissenda. Aspects of various intrinsic, nonsynaptic modifications are expressed by alterations in the excitability of identified photoreceptors in response to the conditioned stimulus. In addition to changes in cellular excitability, changes in synaptic strength between identified neurons have been proposed as a possible mechanism of associative learning in several invertebrate preparations. Here we report that classical conditioning produces differential effects upon the strength of inhibitory monosynaptic connections between identified pairs of type B and type A photoreceptors. The amplitude of IPSPS elicited by an action potential in the medial type $B$ photoreceptor and recorded from medial type $A$ photoreceptors was significantly enhanced in conditioned animals as compared to pseudorandom controls. In contrast, the amplitude of IPSPs elicited by an action potential in the lateral type B photoreceptor and recorded from lateral type A photoreceptors did not show significant synaptic enhancement following conditioning. These results provide additional evidence for differential effects of conditioning upon cellular modifications in identified type A and type B photoreceptors, and further indicate that multiple sites of cellular plasticity exist in the visual system of conditioned Hermissenda.

[Key words: Hermissenda, classical conditioning, photoreceptor, IPSPS, synaptic enhancement, synaptic plasticity]

The visual systcm of Hermissenda has been used extensively in studies of cellular and molecular mechanisms of classical conditioning (for recent reviews, see Crow, 1988; Alkon, 1989). One site of cellular plasticity in conditioned animals is the primary sensory neurons of the pathway mediating the conditioned stimulus (CS) (Crow and Alkon, 1980; Alkon et al., 1982, 1985; Farley and Alkon, 1982; Crow, 1985, 1988; Goh et al., 1985; Farley et al., 1990; Matzel et al., 1990; Frysztak and Crow, 1993). Correlates of conditioning in different types of identified neurons of the CS pathway are expressed by statistically significant increases and decreases in CS-elicited spike frequency, enhanced excitability to extrinsic current, an increase in the

Received May 19, 1993; revised July 29, 1993; accepted Aug. 12, 1993.

We thank Vilma Araujo for technical assistance, and Dr. Ebenezer Yamoah for reading an earlier draft of the manuscript. This work was supported by NIMH Grant MH40860 (to T.C.) and NIMH Research Service Award MH10326 to R.J.F.).

Correspondence should be addressed to Dr. Robert J. Frysztak, Department of Neurobiology and Anatomy, University of Texas Medical School, P.O. Box 20708, Houston, TX 77225.

Copyright (C) 1994 Society for Neuroscience $0270-6474 / 94 / 141245-06 \$ 05.00 / 0$ input resistance of type $B$ photoreceptors, both increased and decreased amplitudes of light-elicited generator potentials, a decrease in spike frequency accommodation, and reductions in the peak amplitudes of several diverse $\mathrm{K}^{+}$currents (Crow and Alkon, 1980; Alkon et al., 1982, 1985; Farley and Alkon, 1982; West et al., 1982; Crow, 1985; Farley et al., 1990; Frysztak and Crow, 1993). The modification in excitability of identified sensory neurons may be a major contributor to changes in the amplitude and duration of complex PSPs and alterations in CSelicited spike frequency recorded in postsynaptic targets following conditioning (Crow, 1988; Alkon, 1989). In addition to the nonsynaptic modification of excitability produced by conditioning, changes in synaptic strength between photoreceptors could also contribute to alterations in CS-elicited activity in postsynaptic neurons. A recent study reported that 5 -HT could produce facilitation of the inhibitory synaptic connections between type B and type A photoreceptors within the eye of $\mathrm{Her}$ missenda (Clark and Schuman, 1992). A role for 5-HT has been proposed in one-trial conditioning of Hermissenda (Crow and Forrester, 1986, 1990, 1991, 1993); however, enhancement of the inhibitory synaptic connections between identified type B and type A photoreceptors has not been previously examined following multitrial classical conditioning of Hermissenda. Here we report that classical conditioning produces enhancement of the amplitude of unitary IPSPs recorded from medial type A photoreceptors that are elicited by single action potentials in medial type $B$ photoreceptors. We found that the enhancement of IPSP amplitude was specific to the synaptic connections between medial type B and medial type A photorccptors, since the synaptic connection between the lateral $\mathrm{B}$ and lateral $\mathrm{A}$ photoreceptors was not enhanced by conditioning.

A preliminary report of these results has been presented in abstract form (Frysztak and Crow, 1992).

\section{Materials and Methods}

Animals. Adult Hermissenda crassicornis were used in the experiments. The animals were obtained from Sea Life Supply, Sand City, CA, and maintained in closed artificial seawater aquaria at $14+1{ }^{\circ} \mathrm{C}$ on a 12 . hr light/dark cycle. Animals were fed small pieces of scallop daily. Behavioral training, testing, and electrophysiological procedures were performed during the light phase of the light/dark cycle.

Baseline test of phototactic behavior. The details of the conditioning procedures and methods for testing phototactic behavior have been described in detail in previous publications (Crow and Alkon, 1978; Crow and Offenbach, 1983; Crow, 1985) and will be described only briefly in this report. Animals were tested prior to training to determine baseline latencies to initiate locomotion in response to a test light. Animals that did not respond within a $20 \mathrm{~min}$ criterion period during the pretraining measurements were not used in the conditioning experiments. Previous research has shown that the increase in the time taken by the animals to locomote into a test light can be accounted for by an 
increase in the latency to initiate locomotion (Crow and Offenbach, 1983). Animals were placed into glass tubes $228 \mathrm{~mm}$ long filled with artificial seawater. A foam plug inserted through an opening confined the animal to one end of the tube. The tubes were attached by spring clips to a modified turntable enclosed in an incubator maintained at $15^{\circ} \mathrm{C}$. Animals were dark-adapted for $12 \mathrm{~min}$ prior to testing phototactic behavior. A light spot $\left(10^{-4}\right.$ watts $/ \mathrm{cm}^{2}$, white light $)$ was projected onto the center of the turntable, illuminating a circular area $15-16 \mathrm{~cm}$ in diameter. The elapsed times to initiate locomotion in the presence of the test light were recorded when a Hermissenda moved between an infrared emitter and a phototransistor at the starting end of each glass tube. When the infrared beam was interrupted, a free-running digital clock was turned off and the time recorded for later data analysis.

Conditioning procedure. Following baseline measurements, animals were assigned to conditioned and pseudorandom control groups. The conditioning phase consisted of 100 trials of the $10 \mathrm{sec}$ CS (light) and unconditioned stimulus (US) (high-speed rotation) each day for 3 consecutive days. The intensity of the CS was the same as the test light used to establish baseline responding of phototactic behavior during the pretest condition. The pseudorandom control group received 100 trials of light and rotation programmed on explicitly unpaired schedules each day for 3 consecutive days.

Postacquisition test. All animals received behavioral testing identical to the pretraining (baseline) test measurement for phototaxis $24 \mathrm{hr}$ after the third conditioning session. Animals that did not initiate locomotion in the presence of the CS within 20 min during the posttest received a maximum latency score. Assessment of conditioning was determined by computing suppression ratios that compared posttraining phototactic behavior with pretraining test scores. The ratio is cxprcssed as $A /(A+$ $B$ ), where $A$ represents pretraining scores and $B$ represents posttraining scores. Conditioned animals exhibited behavioral suppression that was similar in magnitude to previous reports (Crow and Alkon, 1978; Crow and Offenbach, 1983; Crow, 1985).

Intracellular recordings from identified type A photoreceptors. Intracellular recordings from identified pairs of medial or lateral type A and $B$ photoreceptors were collected for both conditioned animals and pseudorandom controls 24 or $48 \mathrm{hr}$ after the last training session. Anatomical and electrophysiological criteria were used to identify specific type A and $\mathrm{B}$ photoreceptors within the eye as previously described (Alkon and Fuortes, 1972).

The circumesophageal nervous systems were removed from the animals and pinned to a Sylgard (Dow Chemical) stage in a recording chamber. The chambcr was filled with artificial seawater of the following composition (mM): $460 \mathrm{NaCl}, 10 \mathrm{KCl}, 10 \mathrm{CaCl}_{2}, 55 \mathrm{MgCl}_{\text {, }}$, buffered with $10 \mathrm{~mm}$ HEPES and brought to $\mathrm{pH} 7.46$ with dilute $\mathrm{NaOH}$. The isolated nervous systems were incubated in a protease solution (Sigma; $0.67 \mathrm{mg} / \mathrm{ml}, 5-7 \mathrm{~min}$ ) to facilitate microelectrode penetration of photoreceptors. Intracellular recordings were only collected from identified type $\mathrm{A}$ and $\mathrm{B}$ photoreceptors. The artificial seawater in the recording chamber was monitored by a thermistor and held at $15 \pm 0.5^{\circ} \mathrm{C}$. Illumination of the isolated nervous system was provided by a tungsten halogen incandescent lamp attached to a fiber optic bundle mounted underneath the recording chamber.

Spike-elicited IPSPS. Following impalement of an identified pair of type A and B photoreceptors, the nervous system was dark-adapted for 12 min before collection of electrophysiological data. The membrane potential of the A photorccptor was maintained at $-60 \mathrm{mV}$ by the passage of extrinsic current. In order to minimize the possible effect of synaptic depression, type B photoreceptors were hyperpolarized to block spontaneous action potentials. There were no consistent differences between groups in the magnitude of hyperpolarizing current required to block spontaneous spikes in type B photoreceptors. Single spikes were elicited in the B photoreceptor by depolarizing current pulses of 150 $200 \mathrm{msec}$ duration. The intertrial interval for eliciting IPSPs was 10 $\mathrm{sec}$, and a minimum of $30-60 \mathrm{sec}$ elapsed after hyperpolarization of the $\mathrm{B}$ photorecpetor before eliciting the first IPSP. A minimum of 10 IPSPs were recorded from each identified type A photoreceptor, and an overall average IPSP amplitude was computed for each animal. The first 10 measurements of IPSP amplitude from each animal were used in histograms to determine the distribution of IPSP amplitudes for each group.

Statistical analysis. Overall effects of conditioning on IPSP amplitudes were assessed with a treatment by trials analysis of variance (Winer, 1962). Mann-Whitney $U$ tests were used to determine the effects of conditioning on phototactic behavior and potential overall differences in IPSP amplitudes at $24 \mathrm{hr}$ and $48 \mathrm{hr}$ following conditioning (Siegel,
1956). Since no significant differences in IPSP amplitudes were found within groups at $24 \mathrm{hr}$ compared to $48 \mathrm{hr}$ after the last training session (see results), the data were combined for the final statistical analysis.

\section{Results}

The CS produced statistically significant suppression of phototactic behavior in conditioned animals as compared to pseudorandom controls $(U=19 ; p<0.001)$ that was similar in magnitude to previously published results (Crow and Alkon, 1978; Crow and Offenbach, 1983). The analysis of IPSP amplitudes was conducted with isolated nervous systems from animals 24 and $48 \mathrm{hr}$ after postconditioning behavioral tests. Statistical analysis revealed that there were no significant differences in IPSP amplitudes for data collected 24 or $48 \mathrm{hr}$ after conditioning for the paired group $(U=16 ; p>0.267)$ or pseudorandom controls $(U=18 ; p>0.531)$. Thus, the overall statistical analyses of the data collected 24 and $48 \mathrm{hr}$ postconditioning were combined.

\section{Spike-elicited IPSPS in lateral type A photoreceptors}

Intracellular recordings werc collccted from dark-adapted pairs of identified medial and lateral type A and B photoreceptors of conditioned and pseudorandom control animals. The eyes of Hermissenda contain five photoreceptors, two type A and three type B (Alkon and Fuortes, 1972). The synaptic interactions between pairs of photoreceptors are mutually inhibitory (Alkon and Fuortes, 1972), although differences in synaptic strength exist between identified pairs of type A and B photoreceptors (Goh and Alkon, 1984; Frysztak and Crow, 1993). The analysis of IPSPs revealed differential effects of conditioning upon spikeelicited PSP amplitudes recorded from identified medial and lateral type A photoreceptors. Figure 1 illustrates representative examples of spike-elicited IPSPs recorded from an identified lateral type $\mathrm{A}$ photoreceptor from the conditioned group and a pseudorandom control group. An action potential elicited in the lateral type $\mathrm{B}$ photoreceptor $(A I, B I)$ produced a unitary IPSP recorded from the lateral type $A$ photorcceptor $(A 2, B 2)$. In the example shown in Figure 1, the amplitude of the IPSP recorded from the lateral type A photoreceptor of the conditioned animal (A2) was nearly identical to the amplitude of the IPSP recorded from the lateral type A photoreceptor of a pseudorandom control animal (B2). The group data shown in the histograms in Figure 2 revealed considerable overlap in the distribution of IPSP amplitudes for the lateral type A photoreceptors of conditioned animals and pseudorandom controls. This conclusion is supported by the results of the ANOVA, showing that the IPSPs recorded from lateral type $A$ photoreceptors were not significantly different in amplitude for paired animals $(N=6)$ as compared to pseudorandom controls $(N=5)\left(F_{1,9}=0.49\right)$. In addition, IPSP amplitudes did not significantly change over the 10 test trials $\left(F_{9.81}=1.52\right)$, and potential interactions between the treatment and test trials were not significant $\left(F_{9,81}=1.16\right)$. These results indicate that synaptic depression did not contribute to changes in IPSP amplitudes over the 10 consecutive test trials. The present findings show that conditioning does not produce a significant change in the IPSP amplitude recorded from the lateral type A photoreceptor and elicited by stimulation of the lateral type $\mathrm{B}$ photoreceptor. Thus, while conditioning has been previously shown to produce enhanced excitability in the lateral typc A photorcceptor (Frysztak and Crow, 1993), synaptic enhancement of the connection between the lateral type 


\section{PAIRED RANDOM}

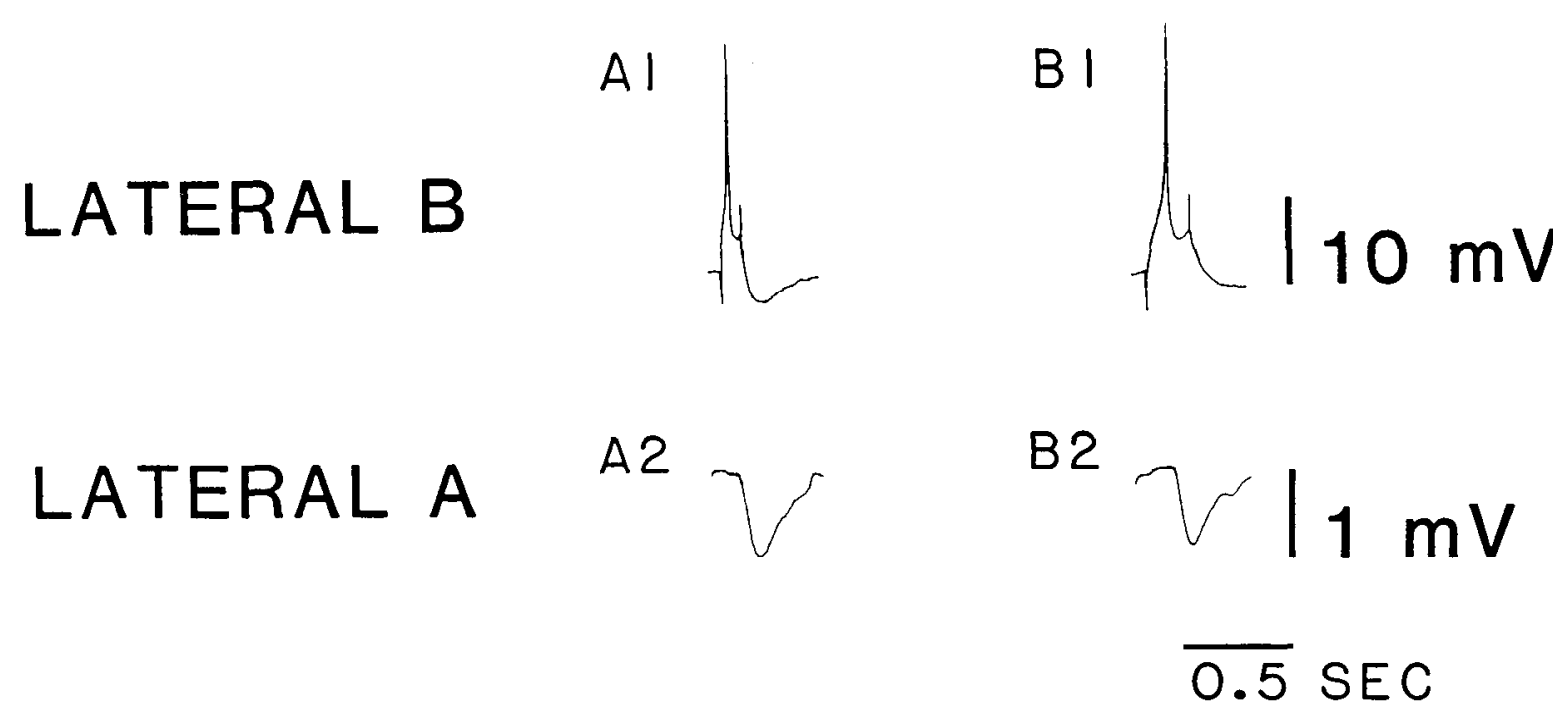

Figure 1. Effects of conditioning on IPSP amplitude in lateral type A photoreceptors: representative examples of spike-elicited unitary IPSPs recorded from lateral type A photoreceptors in a conditioned animal (A2) and a pseudorandom control (B2). Single spikes were elicited in different lateral type B photoreceptors $(A l, B l)$ by a brief $(150-200 \mathrm{msec})$ depolarizing current pulse, while IPSPs were simultaneously recorded in lateral type A photoreceptors $(A 2, B 2)$. The amplitude of the IPSP recorded in the lateral A type $\mathrm{A}$ photoreceptor from the conditioned group $(A 2)$ is similar in amplitude to the IPSP recorded in the lateral A photoreceptor from the pseudorandom control (B2).

B and lateral type A photoreceptors is not observed following classical conditioning.

\section{Spike-elicited IPSPs in medial type A photoreceptors}

We next examined the synaptic connection between the medial type B photoreceptor and medial type A photoreceptor in conditioned and pseudorandom control animals. In contrast to the results from the lateral A photoreceptor, IPSPs recorded from the medial type A photoreceptor were enhanced in conditioned animals as compared to pseudorandom controls. Figure 3 shows representative examples of IPSPs elicited by stimulation of a medial type B photoreceptor and recorded from a medial type A photoreceptor in a conditioned animal and a pseudorandom control animal. An action potential elicited in the medial type B photoreceptor $(A 1, B I)$ produced a unitary IPSP recorded from the medial type A photoreceptor $(A 2, B 2)$. In the example in Figure 3 , the IPSP from the conditioned animal $(A 2)$ is substantially larger in amplitude as compared to the IPSP recorded from the pseudorandom control (B2). The group data shown in the two histograms in Figure 4 revealed that larger IPSP amplitudes were typically recorded in medial type A photoreceptors from conditioned animals as compared to pseudorandom controls. These results show that conditioning produces synaptic enhancement of IPSP amplitudes recorded from medial type A photorcccptors. This conclusion is supported by the results of the analysis of variance for the data shown in Figure 5. Significant overall effects were found in IPSP amplitudes between paired animals $(N=7)$ and pseudorandom controls $(N=7)$ $\left(F_{1.12}=5.91, p<0.05\right)$. The main effect of trials was not significant $\left(F_{9.108}=0.88\right)$, again indicating that the IPSP amplitude was not changing significantly over the 10 consecutive test trials. The interaction between the treatment and test trials was not significant $\left(F_{9.108}=1.36\right)$. In addition to information on signif- icance levels, we computed $\eta^{2}$ as an estimate of effect size (Cohen and Cohen, 1975). Estimation of effect size revealed that approximately $33 \%$ of the variability in IPSP amplitude could be accounted for by the conditioning treatment. These results show that conditioning produces differential enhancement of the synaptic connections between pairs of identified photoreceptors within the eyes of Hermissenda. Synaptic enhancement in conditioned animals is specific to the connection between the medial type $B$ and the medial type A photoreceptor. The synaptic connection between the lateral type B and the lateral type A photoreceptor does not exhibit significant enhancement in condi-

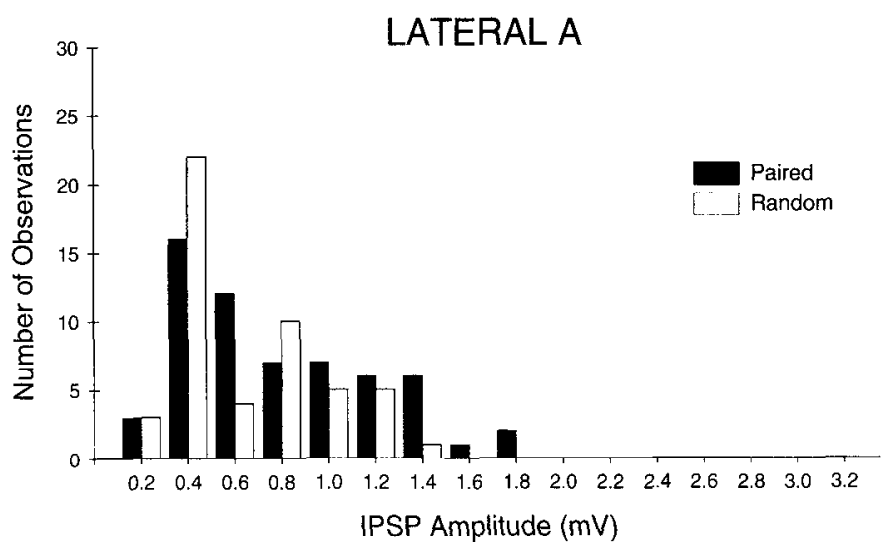

Figure 2. Group data (histograms) displaying IPSP amplitudes recorded from lateral type A photoreceptors of conditioned (paired) animals and pseudorandom controls. Solid bars represent IPSPs recorded from conditioned animals $(N=6)$; open bars represent IPSPs recorded from pseudorandom controls $(N=5)$. A total of 10 IPSPs were collected from each animal. The distribution of the IPSP amplitudes for the two groups were nearly identical. 


\section{PAIRED RANDOM}

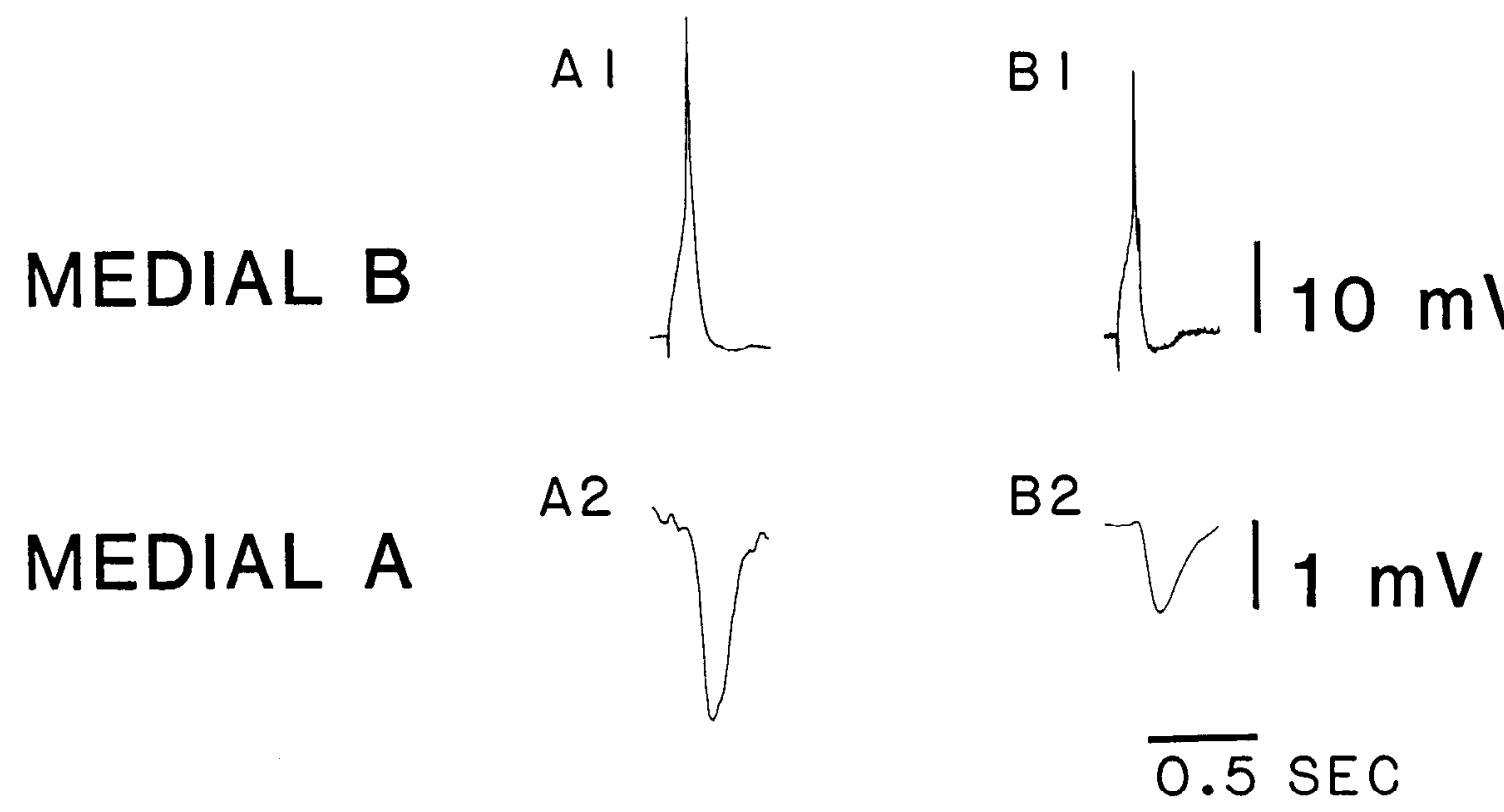

Figure 3. Effects of conditioning on IPSP amplitude in medial type A photoreceptors: representative examples of spike-elicited unitary IPSPs recorded from a medial type $\Lambda$ photoreceptor in a conditioned animal (A2) and a pseudorandom control (B2). Single spikes were elicited in different medial type $B$ photoreceptors $(A 1, B I)$ by a brief $(150 \mathrm{msec})$ depolarizing current pulse, while IPSPs were simultaneously recorded in the medial type A photoreceptors $(A 2, B 2)$. The amplitude of the IPSP recorded in the medial type A photoreceptor from the conditioned group (A2) was larger than that recorded from the pseudorandom control $(B 2)$.

tioned animals, although intrinsic changes in excitability have been previously reported (Frysztak and Crow, 1993).

\section{Discussion}

Cellular neurophysiological studies of the visual system of Hermissenda have identified several examples of intrinsic, nonsy-

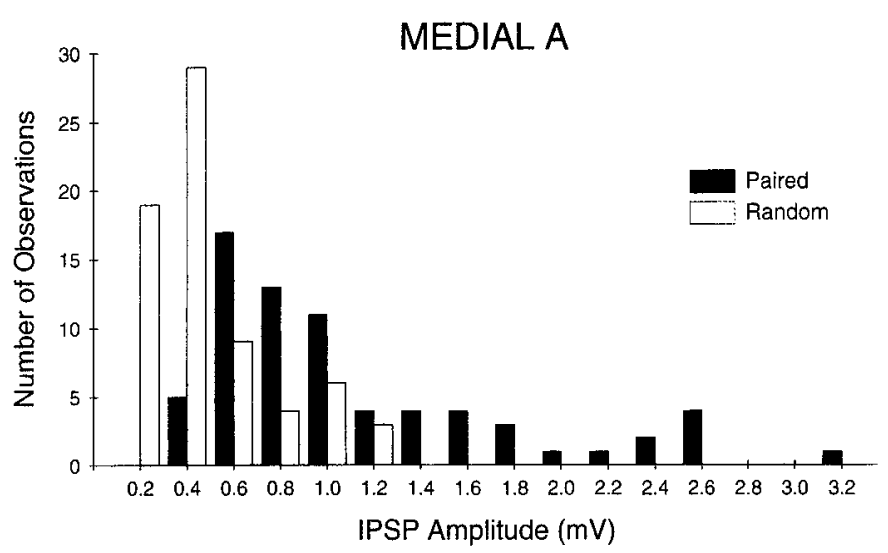

Figure 4. Group data (histograms) showing IPSP amplitudes recordes. from medial type A photoreceptors of conditioned (paired) animals and pseudorandom controls. Solid bars represent IPSPs recorded from conditioned animals $(N=7)$; open bars represent IPSPs recorded from pseudorandom controls $(N=7)$. A total of 10 IPSPs were collected from each animal. The distribution of the IPSPs recorded from conditioned animals shows that the larger values are characteristic of conditioned animals. naptic changes in both type $\mathrm{A}$ and $\mathrm{B}$ photoreceptors following classical conditioning (Crow and Alkon, 1980; Alkon et al., 1982, 1985; Farley and Alkon, 1982; Crow, 1985; Farley et al., 1990). A prominent feature of learning in the Hermissenda nervous system is the significant increase in the input resistance of surgically isolated type B photoreceptors observed following

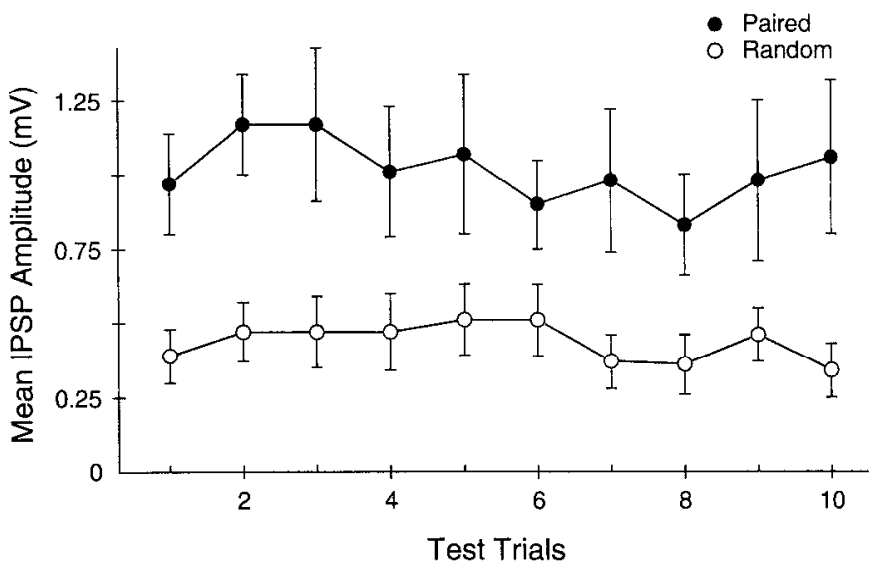

Figure 5. IPSP amplitude does not change during consecutive test trials: group data showing the mean IPSP amplitudes \pm SEM recorded from medial type A photoreceptors in conditioned animals $(N=7)$ and pseudorandom controls $(N=7)$ for 10 consecutive test trials. The intertrial interval between IPSPs was $10 \mathrm{sec}$. Significant main effects of IPSP amplitude were found between paired animals and pseudorandom controls $\left(F_{1, t 2}=5.91, p<0.05\right)$, although the main effect of test trials on IPSP amplitude was not statistically significant $\left(F_{9,108}=0.88\right)$. 
conditioning (Crow and Alkon, 1980; Farley and Alkon, 1982; West et al., 1982). The intrinsic changes in input resistance that have been detected in medial type B photoreceptors may be explained in part by decreases in several diverse $\mathrm{K}^{+}$conductances (Crow and Alkon, 1980; Alkon et al., 1982, 1985). It has been proposed that the decrease in the amplitude of $I_{\mathrm{A}}$ and $I_{\mathrm{K}(\mathrm{Ca})}$ observed in conditioned Hermissenda (Alkon et al., 1982, 1985) would be expected to increase the amplitude of CS-elicited generator potentials recorded from isolated photoreceptors following conditioning (West et al., 1982).

In addition to the changes in input resistance, conditioning has also been shown to produce differential cffects upon the excitability of identified type B photoreceptors (Crow and Alkon, 1980; Farley and Alkon, 1982; Crow, 1985). Although not specifically identified as medial type B photoreceptors, Alkon et al. (1985) have proposed that medial type B photoreceptors exhibit an increase in the amplitude of light-elicited generator potentials (West et al., 1982), and an increase in light-elicited spike frequency (Farley and Alkon, 1982). In contrast to the effect of conditioning on the medial type B photoreceptor, lateral type B photoreceptors exhibit a decreased excitability involving both a reduction in the amplitude of CS-elicited generator potential plateau phases and spike frequency (Crow, 1985). In addition to the differential changes in excitability of medial and lateral type B photoreceptors produced by conditioning, we now provide evidence for differential enhancement of photoreceptor synaptic connections between identified type B and type A photoreceptors of conditioned Hermissenda. We found enhancement of IPSPs in the connection between the medial type B and medial type A photoreceptor. In contrast to these results, the connection between the lateral type B and lateral type A photoreceptor did not exhibit significant changes in IPSP amplitude following conditioning. These results support the general finding of differential effects on excitability of type $B$ photoreceptors in conditioned animals. Specifically, the medial type B photoreceptor exhibits both enhanced excitability, expressed by an increase in CS-elicited generator potential amplitude and spike frequency, and synaptic enhancement. The lateral type B photoreceptor, however, shows diminished excitability, a reduction in CS-elicited generator potential amplitude and spike frequency, and no significant change in the amplitude of spike elicited IPSPs recorded from lateral type A photoreceptors.

Our present findings show that there are multiple sites of cellular plasticity produced by classical conditioning in identified sensory neurons. Intrinsic changes in excitability expressed by changes in the amplitude of CS-elicited generator potentials were originally detected following conditioning in surgically isolated photoreceptors. These preparations isolate the spike-generating zone and all synaptic input from the region of phototransduction (Alkon and Fuortes, 1972). The decrease in the amplitude of $\mathrm{K}^{+}$currents observed following conditioning most likely is contributing to the changes in CS-elicited generator potential amplitude. The example of synaptic enhancement reported in this study may involve mechanisms affecting the release of neurotransmitter from the medial type $B$ photoreceptor, since significant changes in the input resistance of medial type A photoreceptors in the voltage range of the IPSP were not detected. In addition, the connections between photoreceptors have been shown previously to be monosynaptic (Crow et al., 1979). However, we cannot completely rule out the possibility of a postsynaptic contribution to the enhanced IPSP recorded from type A photoreceptors. In addition, we have previously reported that the excitability of lateral type A photoreceptors to extrinsic current is enhanced and spike frequency accommodation is decreased by conditioning (Frysztak and Crow, 1993). Taken collectively, we now have evidence for changes in the amplitude of CS-elicited generator potentials, spike frequency elicited by the CS, and strength of monosynaptic connections between identified photoreceptors of conditioned animals. The mechanisms responsible for generator potential enhancement and decreased spike frequency accommodation that we previously reported (Frysztak and Crow, 1993) may be different and involve different loci within the identified photoreceptors. It is unlikely that the previously reported reduction in $I_{\mathrm{A}}$ in medial type B photoreceptors (Alkon et al., 1982) is responsible for the enhancement of IPSPs recorded from the medial type A photoreceptor, since the half-inactivation point $\left(h_{0.5}\right)$ for $I_{\mathrm{A}}$ is close to the typical resting potential of type $\mathrm{B}$ photoreceptors (Acosta-Urquidi and Crow, 1990). Thus, $I_{\mathrm{A}}$ exhibits strong inactivation at potentials more positive than the resting membrane potential and would not be expected to contribute to spike broadening in the type B photoreceptors.

Studies of Aplysia sensory neurons have shown that several examples of behavioral and cellular plasticity involve changes in the strength of synaptic connections between sensory and motor neurons (for recent review, see Byrne and Crow, 1992). In addition, there is considerable evidence for enhanced excitability in Aplysia sensory neurons associated with behavioral plasticity (Klein et al., 1986; Walters, 1987; Billy and Walters, 1989). While it has been suggested that both processes may involve a common mechanism (Clark and Schuman, 1992), recent evidence in Aplysia suggests that aspects of spike broadening associated with synaptic facilitation and enhanced excitability may involve different mechanisms (Baxter and Byrne, 1990; Mercer et al., 1991; Sugita et al., 1992).

Recently, evidence was presented that 5-IIT application produced synaptic facilitation of connections between type B and type A photoreceptors of Hermissenda (Clark and Schuman, 1992). Previous research has shown that 5-HT contributes to one-trial conditioning of Hermissenda (Crow and Forrester, 1986; Crow et al., 1991). However, while the application of 5-HT as a substitute for the US has been shown to be sufficient to produce one-trial learning, the role of 5-HT in multiple-trial classical conditioning has not yet been established.

The question can be raised concerning the functional significance of synaptic enhancement to the generation of reduced phototactic behavior and the activity of the neural circuitry thought to support conditioning. Interestingly, enhancement of the medial B to medial A synaptic connection would not be expected to contribute to CS-elicited cellular correlates recorded in the medial type A photoreceptor. Previous research has shown that the medial A photorcceptor does not exhibit conditioning specific changes in CS-elicited spike activity (Frysztak and Crow, 1993). The synaptic enhancement that we observed following conditioning in the medial A photoreceptor may tend to counteract any intrinsic enhanced excitability produced by conditioning, and thus the net effect would be no significant change in CS-elicited spike activity recorded from medial type A photoreceptors. While the enhancement of IPSPs recorded from medial type A photoreceptors does not contribute to modification of phototactic behavior. other postsynaptic targets of the medial type B photoreceptor could potentially contribute to the 
suppression of phototaxis if the synaptic connections showed similar enhancement following conditioning.

Taken collectively, our results indicate that different sites of plasticity exist within the sensory neurons of the CS pathway in conditioned animals. First, the lateral type A photoreceptor does not show enhancement of the type B-elicited IPSP, but does exribit enhanced excitability to the CS, and enhanced excitability and less spike frequency accommodation to extrinsic current. Second, the medial type A photoreceptor does show enhancement of the type B-elicited IPSP, but does not exhibit intrinsic changes in excitability. Since the lateral type A photorcceptor exhibits both a decreased generator potential amplitude and enhanced spike activity to both the CS and to extrinsic current, and the medial A type photoreceptor exhibits synaptic enhancement, the possibility exists that three different sites or loci within the visual system are modified by conditioning. These three sites may involve three very different cellular mechanisms, although this is yet to be established.

\section{References}

Acosta-Urquidi J, Crow T (1990) 5-HT modulates two distinct $\mathrm{K}^{+}$ currents in Hermissenda type B photoreceptors. Soc Neurosci Abstr $16: 20$.

Alkon DL (1989) Memory storage and neural systems. Sci Am 261(1): 42-50.

Alkon DL, Fuortes MGF (1972) Responses of photoreceptors in Hermissenda. J Gen Physiol 60:631-649.

Alkon DL, Lederhendler I, Shoukimas JJ (1982) Primary changes of membrane currents during retention of associative learning. Science 215:693-695.

Alkon DL, Sakakibara M, Forman R, Harrigan J, Lederhendler I, Farley $J$ (1985) Reduction of two voltage-dependent $\mathrm{K}^{+}$currents mediates retention of a learned association. Behav Neural Biol 44:278-300.

Baxter DA, Byrne JH (1990) Differential effects of cAMP and serotonin on membrane current, action potential duration, and excitability in somata of pleural sensory neurons of Aplysia. J Neurophysiol 64:978-990.

Billy AJ, Walters ET (1989) Long-term expression and sensitization of mechanosensory receptive fields in Aplysia support an activitydependent model of whole-cell plasticity. J Neurosci 9:1254-1262.

Byrne JH, Crow T (1992) Examples of mechanistic analyses of learning and memory in invertebrates. In: Learning and memory (Martinez JL, Kesner RP, eds), pp 329-358. New York: Academic.

Clark G, Schuman E (1992) Snails tails: Initial comparisons of synaptic plasticity underlying learning in Hermissenda and Aplysia. In: Neuropsychology of memory (Squire LR, Butters N, eds), pp 588-602. New York: Guilford.

Cohen J, Cohen P (1975) Applied multiple regression/correlation analysis for the behavioral sciences. Hillsdale, NJ: Erlbaum.

Crow $T$ (1985) Conditioned modification of phototactic behavior in IIermissenda. II. Differential adaptation of B-photoreceptors. J Neurosci 5:215-223.

Crow T (1988) Cellular and molecular analysis of associative learning and memory in Hermissenda. Trends Neurosci 11:136-142.

Crow T, Alkon DL (1978) Retention of an associative behavioral change in Hermissenda. Science 201:1239-1241.

Crow T, Alkon DL (1980) Associative behavioral modification in Hermissenda: cellular correlates. Science 209:412-414.
Crow T, Forrester J (1986) Light paired with serotonin mimics the effect of conditioning on phototactic behavior in Hermissenda. Proc Natl Acad Sci USA 83:7975-7978.

Crow T, Forrester J (1990) Inhibition of protein synthesis blocks longterm enhancement of generator potentials produced by one-trial in vivo conditioning in Hermissenda. Proc Natl Acad Sci I ISA 87:44904494.

Crow T, Forrester J (1991) Light paired with serotonin in vivo produces both short- and long-term enhancement of generator potentials of identified B-photoreceptors in Hermissenda. J Neurosci 11:608-617.

Crow T, Forrester J (1993) Down-regulation of protein kinase C and kinase inhibitors dissociate short- and long-term enhancement produced by one-trial conditioning of Hermissenda. J Neurophysiol 69: 636-641.

Crow T, Offenbach N (1983) Modification of the initiation of locomotion in Hermissenda: behavioral analysis. Brain Res 271:301-310.

Crow T, Heldman E, Hacopian V, Enos R, Alkon DL (1979) Ultrastructure of photoreceptors in the eye of Hermissenda labeled with intracellular injection of horseradish peroxidase. $J$ Neurocytol 8:181195

Crow T, Forrester J, Williams M, Waxham MN, Neary JT (1991) Down-regulation of protein kinase $\mathrm{C}$ blocks 5-HT-induced enhancement in Hermissenda B-photoreceptors. Neurosci Lett 12:107-1 10.

Farley J, Alkon DL (1982) Associative neural and behavioral change in Hermissenda: consequences of nervous system orientation for lightand pairing-specificity. J Neurophysiol 48:785-807.

Farley J, Richards WG, Grover LM (1990) Associative learning changes intrinsic to Hermissenda type A photoreceptors. Behav Neurosci 104: 135-152.

Frysztak RJ, Crow T (1992) Synaptic interactions between pairs of identified type A and B photoreceptors in conditioned Hermissenda. Soc Neurosci Abstr 18:15.

Frysztak RJ, Crow T (1993) Differential expression of correlates of classical conditioning in identified medial and lateral type A photoreceptors of Hermissenda. J Neurosci 13:2889-2897.

Goh Y, Alkon DL (1984) Sensory, interneuronal, and motor interactions within Hermissenda visual pathway. J Neurophysiol 52:156168.

Goh Y, Lederhendler I, Alkon DL (1985) Input and output changes of an identified neural pathway are correlated with associative learning in Hermissenda. J Neurosci 5:536-543.

Klein M, Hochner B, Kandel ER (1986) Facilitatory transmitters and cAMP can modulate accommodation as well as transmitter release in Aplysia. Proc Natl Acad Sci USA 83:7994-7998.

Matzel LD, Lederhendler II, Alkon DL (1990) Regulation of shortterm associative memory by calcium-dependent protein kinase. $\mathrm{J}$ Neurosci 10:2300-2307.

Mercer AR, Emptage NJ, Carew TJ (1991) Pharmacological dissociation of modulatory effects of serotonin in Aplysia sensory neurons. Science 254:1811-1813.

Sicgel (1956) Nonparametric statistics for the behavioral sciences. New York: McGraw-Hill.

Sugita S, Goldsmith JR, Baxter DA, Byrne JH (1992) Involvement of protein kinase $C$ in serotonin-induced spike broadening and synaptic facilitation in sensorimotor connections of Aplysia. J Neurophysiol 68:643-651.

Walters ET (1987) Multiple sensory neuronal correlates of site-specific sensitization in Aplysia. J Neurosci 7:408-417.

West A, Barnes ES, Alkon DL (1982) Primary changes of voltage responses during retention of associative learning. J Neurophysiol 48 : 1243-1255.

Winer BJ (1962) Statistical principles in experimental design. New York: McGraw-Hill. 